\title{
Postgraduates' perceptions regarding their mastery level of educational research skills at the Palestinian faculties of education and ways to develop these skills
}

\author{
Mahmoud Mohammed Omar Assaff ${ }^{1}$ and Khalil Abdullah Aburezeq ${ }^{2 *}$ \\ ${ }^{1}$ Palestinian Ministry of Education, West of Gaza Directorate, Palestine. \\ ${ }^{2}$ Faculty of Education, Islamic University of Gaza, Palestine. \\ Accepted 10 July, 2018
}

\begin{abstract}
Educational research is a significant tool for developing the field of education for students and thus a certain development to society. The aim of the study is to identify the level of mastering educational research skills among postgraduates from their perceptions at faculties of education at Palestinian universities and also to identify the ways for promoting the educational research skills. The researchers used the descriptive analytical approach. The participants of the study contained 109 postgraduates, both MA and Ph.D. postgraduates. The tool of study is a questionnaire that was distributed to the postgraduates to identify their views towards mastering the educational research skills. The results of the study showed that there were high levels of mastering to the educational research skills according to the postgraduates' perceptions. The study also showed that there were no statistically significant differences in the responses of postgraduates due to gender variable and Ph.D. students have more skills than master students. The study recommended that Palestine universities should focus on practical aspects when teaching research method course.
\end{abstract}

Keywords: Educational research, skills, faculties of education.

*Corresponding author. E-mail: khalilaburezeq@hotmail.com.

\section{INTRODUCTION}

Today, the world lives in a frantic race to obtain the maximum scientific knowledge derived from all the sciences that lead to progress and advancement. Scientific knowledge is the key to progress and development; it is essential for humans to overcome obstacles and to achieve the desired goals. Scientific knowledge also provides persons with strategies allowing them to correct errors and take new actions that enable them to achieve their aspirations in life. This knowledge is not mere reading or reviewing books, rather it is the intelligence of somebody to detect many of the phenomena that he/she does not know. To gain this knowledge, the academic institutions are the main centers of this vital scientific activity as they have the key role to train and encourage students to collect information and present it in a sound scientific framework. That frame aims to solve all humanitarian problems. Thus, it could be said that the philosophy of scientific research to solve peoples' problems.

Kaddoumi (2016) stated that despite the significance of educational research and its role in the development of education, many educational events such as conferences and seminars have confirmed that the status of educational research in the Arab countries is not satisfactory. This status is one of the reasons that cause setback to educational process. It suffers from a real crisis, which requires all the persons interested in research to study the aspects of that crisis and submit their practical proposals to get out of this problem. Their proposals could increase the efficiency of research in the educational system of the Arab countries, including Palestine. In this regard, El Barghouti and Abu Samra 
(2007) mentioned that the Arab universities spend $1 \%$ of its budget on scientific research. This is surely a very low percentage and shows the shortcomings in research.

Braimoh and Alade (2005) added that scientific research is one of the cornerstones of the activities of universes that support higher education institution. Scientific research is an important aspect for university professors. If they seek promotion, they should publish researches as well as teaching active classes. Scientific research improves the level of academic performance and raises the university's status and rank all over the world.

Al-Osaimi (2010) explained that the most important sources of scientific research are the scientific theses that are issued by universities as their contribution to the specialized knowledge. They usually deal with subjects that are chosen objectively under the supervision of professors who represent references in their fields. These theses should follow the process of reviewing by professors to inspect whether these theses are contributions produced by students themselves or not.

Theses and dissertations are considered one of the most important outputs of university to the society to contribute to solve the problems facing it. Universities are making continuous efforts in training and qualifying researchers during their university studies to enable them acquire research skills and demonstrate their ability in scientific research. Thus, the way the researchers present their works reflects the power of the university and its programs to produce qualified researchers (Metcalfe and Fenwick, 2009).

The researchers consider that the faculties of universities, in general, and the college of graduate studies, in particular, are the most important places to qualify specialized cadres in different branches of knowledge. They are supposed to prepare students well and that their research should meet the needs of their community.

Educational research, whether master's, doctoral or otherwise, requires many research skills. Therefore, researchers can successfully complete their research. Kojak (2007) explained a number of common problems face beginner researchers in educational research related to: writing the research problem, proposal, the formulation of problem's questions, hypotheses and limits, defining key terms, in addition to the design and methodology of research. They also face difficulties in writing the section of related literature, information for the theoretical framework, errors in data analysis and conclusion of the research. Kojack also added that the researchers commit mistakes in research ethics which violate the rules of writing.

One of the popular sources for the quality and level of educational research is the article that was written in The Australian newspaper, entitled 'The Problem with Educational Research'. In that article, Buckingham explained the shortcomings and the deficits of the educational research in Australia as it is quantitative rather than qualitative. There is use for numbers and data at the expense on interpretation and providing qualitative data (Buckingham, 2005:8).

In the same point, the Australian Council of Deans of Education (ACDE) acknowledged the low financial support of educational research. They also expressed the state of educational research as a "serious decline in educational research funding and effort" that was brought about by "the combined effects of general underresourcing of the area" and "a fairly malevolent set of de facto research measures based solely on a limited theory of knowledge production" (ACDE, 2005:12). These issues indicated that there is low quality of educational research and that made the researcher conduct this research to know the Palestinian postgraduates' level on conducting educational research.

\section{Importance of scientific research}

Educational research occupies a prominent place in our modern era. Al-Qasim (2007) and Al-Agha (2000) noted that scientific research in the field of education is important for the following reasons:

- It provides basic information about educational work as it is used in policy and educational decision-making.

- It qualifies students to deal with educational problems based on scientific foundations. It helps them to apply what they have learned in the field of educational.

- It contributes to find the best designs for learning environments and organize them in scientific grounds.

- It works to improve and follow the developments and requirements of change in life.

- It shows the least outcomes of the field of education.

- It is characterized by spacious environment that is composed of various aspects of different interdependences.

\section{Educational research skills}

The specialists in educational research have different views to agree on a list of the skills of educational research. Some of the scholars confined them in several stages, while others talked about the skills of scientific research in general without specifying certain skills to education field. Therefore, after the researchers' review to many studies and educational literature such as the study of Feldon et al. (2011), Ammar (2015), and Atwan (2011). The researcher has come to divide these skills into four domains:

First domain: The research skills of the study framework. These skills include: selecting the title correctly, writing the introduction, writing the research problem, formulating the objectives, determining the importance of the research, writing the hypotheses, 
defining the limits of the research and its terms, making the necessary forms and tables for research, documenting references and quotations in a scientific manner, using language and writing rules appropriately, and the ability to deal with different databases.

Second domain: The skills of writing literature review. These skills include: presenting previous studies, commenting on them, categorizing them into domains, and compare them with the current research.

Third domain: The skills of study methodology and procedures. These skills include: determining the appropriate approach to the subject of the study, describing the population of the study, selecting and identifying the sample, building the research tools, and selecting the appropriate statistical methods.

Fourth domain: The skills to the study outcomes, and recommendations. These skills include: interpreting the results in a sound scientific manner, linking the results of the study meaningfully with the previous studies, writing the recommendations appropriately, and formulating research recommendations for future studies that are applicable to be investigated.

In educational research, empirical questions are minor, values are central, and philosophical investigation is central to the determination of these. Philosophy is the determinant for policy and practice; virtue is controlled by logic (Clark, 2013).

\section{Problem of the study}

Scientific research is a very vital aspect for any society. It is the source of knowledge and the guide to many discoveries. If universities teach their students the ways of conducting research, society will have scholars and researchers of high quality. Since there is great importance to scientific research, the researchers conduct this research to find out the level of mastering educational research skills among Palestine postgraduates in the faculties of education, selecting the Islamic University of Gaza as the case study of this research. To achieve the study aims, the researchers addressed the following questions:

\section{Study questions}

1. What are the necessary educational research skills should be possessed by postgraduates at the Faculty of Education at the Islamic University of Gaza?

2. To what extent do postgraduates of Faculty of Education at the Islamic University of Gaza master the educational research skills from their perception?
3. What are the ways to enhance postgraduates of Faculty of Education at the Islamic University of Gaza with the educational research skills from perception?

4. Are there any statistically significant differences in the average responses of postgraduates in Faculty of Education at the Islamic University of Gaza towards their mastery of educational research skills due to gender variable (male - female)?

5. Are there any statistically significant differences in the average responses of postgraduates in Faculty of Education at the Islamic University of Gaza towards their mastery of educational research skills due to degree variable (master - Ph.D.)?

\section{Study hypotheses}

1. There are no statistically significant differences in the average responses of postgraduates of Faculty of Education at the Islamic University of Gaza towards their mastery of educational research skills due to gender variable (male - female).

2. There are no statistically significant differences in the average responses of postgraduates of Faculty of Education at the Islamic University of Gaza towards their mastery of educational research skills due to degree variable (master - Ph.D.).

\section{Objectives of the study}

1. To identify the necessary educational research skills among postgraduates of Faculty of Education at the Islamic University of Gaza?

2. To find out to what extent do the postgraduates in Faculty of Education at the Islamic University of Gaza have the ability to conduct educational research from their perception.

3. To find out how to enhance the postgraduates of Faculty of Education at the Islamic University of Gaza with educational research skills from their perception.

4. To detect gender variable (male - female) significant differences in the average responses of postgraduates of Faculty of Education at the Islamic University of Gaza towards their ability to conduct educational scientific research

5. To reveal degree variable (Master - PhD) significant differences in the average responses of postgraduates of Faculty of Education at the Islamic University of Gaza towards their ability to conduct educational research.

\section{Significance of the study}

1. The study highlights the research skills needed by postgraduates when they write their scientific theses and published researches. 
2. The study may benefit university professors when they prepare study plan for the programs of postgraduate studies.

3. The study may open the way for postgraduates and others who are interested in the work of educational research to know more about the skills of educational research needed for conducting researches.

\section{Study key terms}

\section{Educational research}

The researchers operationally define research as all researches, papers, articles, studies, dissertations and theses that are conducted in various fields of education by graduate students at Faculty of Education at the Islamic University of Gaza.

\section{Educational research skills}

The researchers operationally define the educational research skills as a set of performances or abilities that must be possessed by postgraduates at Faculty of Education at the Islamic University in Gaza. These skills help postgraduates to conduct various educational researches such as: to prepare scientific theses and dissertations in systematic and planned steps in the least time and effort.

\section{Postgraduate students}

These are the students who are enrolled in the programs offered by Faculty of Education at the Islamic University of Gaza after the bachelor's degree, whether master students or Ph.D. students.

\section{LITERATURE REVIEW}

In this section, the researchers present previous studies that have similar nature of the current study title. The researchers collected the most recent studies in this field and discuss the results of this research with them. The researchers listed them from the recent to the oldest as follows:

The first study is very close to the current study. Ben Tarif and Tweissi (2017) aimed to identify the status of scientific research at the University of Jordan from the postgraduates' points of view. The researchers used the descriptive analytical approach and chose 104 postgraduates at the humanities faculties and the scientific faculties at the University of Jordan. The study tool was a questionnaire that was consisted of five domains and was distributed to know the views of the postgraduates and their ideas to develop scientific research. The study showed that there is a difference in the average responses of the postgraduates to the status of scientific research. The study reached the scientific research at the University of Jordan is weak. They recommended establishing an independent body for scientific research at the university that serves research and focuses on the practical aspects of writing researches.

Of a similar study, Al Rafiae (2016) study aimed at revealing the postgraduates' degree of enabling to scientific research skills and the ways to overcome the obstacles of conducting scientific research from the postgraduates' points of view in Saudi Arabia. The researcher used the mixed mode approach (qualitative and quantitative). The study reviewed the views of 465 graduate students at King Khalid University, in addition to analyzing the content of 60 master theses and doctoral dissertations. The study tool was a questionnaire distributed to the study participants to reveal the degree of mastering educational skills among postgraduates. Also, the study used a content analysis card to analyze the content of the scientific theses to know the quality of these theses. The most important results of the study showed that postgraduate students possess advanced skills in scientific research, in addition to the existence of statistically significant differences in the difficulties of scientific research skills among students due to the gender variable in favor of females.

The study of Al Rafiae (2016) used new tool to really examine the level of mastering research skills through analyzing the content of theses. The researchers think that using such tool reflects the status of educational researches at King Khalid University. However, this tool requires experienced and qualified researchers to critically comment on the theses and find the deficiencies.

One of the previous studies in America is Feldon et al. (2011) study that aimed to evaluate the research skills among postgraduates in the United States. The researchers viewed many articles in this spot to know if there is impact to the graduate students' teaching experiences on their methodological research skills. The study indicated that the students who taught and conducted research demonstrate significantly greater improvement in their abilities to generate testable hypotheses and design valid experiments.

Al-Qahtani (2013) study is close to the current study as it was applied at faculty of education. The study aimed to identify the problems of research skills that are experienced by female postgraduate students in Faculty of Education at King Saud University from their points of view. The study also aimed to identify the reasons of weakness in using these skills and search for ways to avoid weakness. The researcher used the survey method with 187 students at Faculty of Education at King Saud University. The study tool was a questionnaire to collect data regarding research skills of female students. After analyzing the questionnaires collected, the study showed that there is a clear weakness in applying the research 
skills. The study also showed that there is lack of appropriate methods in teaching and training programs in the field of research. The study revealed that the ways to develop research skills is to use advanced and specialized courses in English at the postgraduate level. This will ease the process of surveying and searching articles. In addition, practical training using statistical programs should be conducted.

It is transparent that until now there is deficit in the skills of scientific research among the Arab students. As the studies tell, this weakness is due to the lack of practice.

A new study sought to find out the perceptions regarding scientific research. Lulu and Abu Camille (2013) study aimed at diagnosing the postgraduates' understanding to educational scientific research at faculties of education in Gaza. The researchers used the descriptive approach and took the views of 82 graduate students who were enrolled at the two faculties of education: The first is the Islamic University of Gaza and the second is Al-Azhar University of Gaza. The study tool was an exam to diagnose the postgraduates' understanding to scientific research. The study tested the postgraduates using 20 concepts of educational research. The study revealed that $40 \%$ of these concepts are wrongly perceived and that the postgraduates have wrong alterative perceptions/understandings regarding the scientific research concepts. This result showed weakness in the postgraduates' understanding to scientific research. The study showed that there is no effect to gender as both male and female showed weakness. The study also indicated that postgraduates of the Islamic University of Gaza showed more understanding to scientific research unlike the postgraduates of Al-Azhar University of Gaza.

Al-Muqbel (2012) study aimed to identify the level of the skills of scientific research among the students of Taibah University in Saudi Arabia and to identify the reasons for their weakness in the field of research skills. The study also aimed to develop a framework to cope with this weakness. The researcher used the analytical descriptive method. The participants were 130 students from the last level at the Faculty of Education. The study used a questionnaire to measure the views of the students. The most important results of the study told that all the respondents agreed that they do not know how to write a scientific research and do not know how to search for the references. The results showed that the faculty of education did not assign a course of research methods to the students before 2006 and that there is one course regarding scientific research is being taught.

\section{Commenting on previous studies}

The topic of educational research skills has attracted the interest of many researchers because of its great importance to the undergraduates in general and to the postgraduates in particular. The majority of studies showed weakness among postgraduates in the Arab universities who suffer from lacking to the skills of research. This weakness is generated from the absence of the practical sides during teaching the courses. This is in addition to the lack of the quality of teaching scientific research methods.

These results that show weakness in writing scientific researches among Arab students urge the researchers of this current research to investigate the level of writing educational research among the Palestine postgraduates.

\section{METHODOLOGY}

\section{Study sampling}

The study population is the total number of postgraduate students at faculty of education in Palestine universities whose number is 392 . The sample of the study included 109 postgraduate students in the two levels (master and Ph.D.). There are 25 of them study Ph.D. They are officially in the second semester of the academic year 2017/2018 (Table 1).

Table 1. Distribution the study sample according to its variables (gender and level).

\begin{tabular}{llcc}
\hline Variable & Category & Number & Percentage \\
\hline \multirow{2}{*}{ Gender } & Male & 42 & 38.53 \\
& Female & 67 & 61.48 \\
& & & \\
\multirow{2}{*}{ Level } & Master & 89 & 81.65 \\
& Ph.D. & 20 & 18.35 \\
\hline
\end{tabular}

\section{Study instrument}

After reviewing the educational literature and many previous studies such as Al-Rafai (2016), Al-Qahtani (2013) and Al-Muqbel (2012), and after consulting many university professors and specialists in the field of educational research, the researcher prepared a questionnaire that comprises five domains to determine the degree of mastering research skills by the postgraduates' perceptions at Faculty of Education at the Islamic University of Gaza. The questionnaire primarily contained 44 items. After consulting the referees who specialized in educational research and making the necessary adjustments, the researcher reached a final version of the questionnaire which included 39 items, classified under 4 domains as stated in Tables 2 and 5 .

Table 2 shows that the instrument was prepared to 
Table 2. Description of the domains of the study tool.

\begin{tabular}{clc}
\hline No. & Domain & No. of items \\
\hline 1 & The skills of the general framework of the study & 13 \\
2 & The skills of writing the theoretical background and the literature review & 10 \\
3 & The procedures of the study methodology & 8 \\
4 & The skills of writing the study outcomes and recommendations & 8 \\
Total items of the study instrument & 39 \\
\hline
\end{tabular}

measure the level of mastering the educational research skills among the Palestinian postgraduates which focused on 4 domains such as: framework, literature review, methodology, and outcomes. The researchers consider that this is a suitable tool as it covers the various aspects of any research.

\section{Internal consistency}

The validity of the internal consistency of the study tool was verified by applying the questionnaire to a pilot sample of 32 postgraduates from the total sample of the study. The correlation coefficient of the questionnaire items of the study instrument were calculated as shown in Table 3.

It can be noticed from Table 3 that correlation coefficients ranged between 0.525 and 0.869 , and all these values are statistically significant at 0.01 . This confirms the consistency of the items of the questionnaire.

\section{Reliability of the study instrument}

The researcher checked the reliability of the study instrument by calculating the Cronbach's Alpha coefficient as the appropriate method in such cases. It determines the reliability of the responses to the questionnaire items. The coefficient of Cronbach's Alpha reliability for each domain was calculated and the total sum as shown in Table 4.

Table 4 shows the values approximation of stability coefficient of the study domains. The lowest value was 0.933, while the highest value was 0.949. The total stability coefficient of the study instrument was 0.979 . All these values are high values indicating the reliabilty of the study instrument.

\section{Study scale}

The researchers used five-degree scale to ensure the answers by postgraduates to the items of the study questionnaire. The scale was: very high (5 degrees), high (4 degrees), moderate (3 degrees), low (two degrees), very low (one degree). In order to interpret the total postgraduates' responses to the questionnaire, the researchers adopted the following scale to judge the degree of mastering educational research skills by graduate students:

Level 1: Low, if the arithmetic mean of the postgraduates' responses range from $1.00-2.33$.

Level 2: Medium, if the arithmetic mean of the postgraduates' responses range from 2.34 - 3.67.

Level 3: High, if the arithmetic mean of the postgraduates' responses range from 3.68 - 5.00.

\section{RESULTS}

\section{Results of the first question}

The first question is stated as "What are the necessary research skills should be possessed by postgraduates at the Faculty of Education at the Islamic University of Gaza?"

This is a question of qualitative nature and in order to answer it, the researchers first investigated the literature review that is related to the title of the study. After reviewing many related studies, the researchers built their preliminary list of skills of educational research. Then, the researcher consulted a panel of referees, who are specialist in educational research to validate the preliminary list. After taking their comments and making the changes required, the researchers reached the current and the reliable list of the study. This list also used to check the mastery of educational research skills among the postgraduates. Table 5 shows the results of the first question.

As Table 5 shows, there are 4 domains and 39 items distributed under these domains. The first domain was 'The skills of the general framework of the study'. It contained 13 skills. The second domain 'The skills of writing the theoretical background and the literature review'. It contained 10 skills. The third domain, 'The procedures of the study methodology,' contained 8 skills. The fourth domain, 'The skills of writing the study outcomes and recommendations,' had 8 skills.

This list is distributed in form of questionnaire to the postgraduates at Faculty of Education at the Islamic University of Gaza to take their opinion about the degree of mastering skills of educational research (Appendix 1). 
Table 3. Correlation coefficients of the items of the study instrument with the total degree.

\begin{tabular}{cccccc}
\hline Item & Correlation coefficients & Item & Correlation coefficients & Item & Correlation coefficients \\
\hline 1 & $0.870^{* *}$ & 14 & $0.640^{* *}$ & 27 & $0.700^{* *}$ \\
2 & $0.791^{* *}$ & 15 & $0.620^{* *}$ & 28 & $0.633^{* *}$ \\
3 & $0.649^{* *}$ & 16 & $0.831^{* *}$ & 29 & $0.698^{* *}$ \\
4 & $0.659^{* *}$ & 17 & $0.839^{* *}$ & 30 & $0.811^{* *}$ \\
5 & $0.787^{* *}$ & 18 & $0.737^{* *}$ & 31 & $0.721^{* *}$ \\
6 & $0.601^{* *}$ & 19 & $0.784^{* *}$ & 32 & $0.783^{* *}$ \\
7 & $0.797^{* *}$ & 20 & $0.749^{* *}$ & 33 & $0.841^{* *}$ \\
8 & $0.691^{* *}$ & 21 & $0.64^{* *}$ & 34 & $0.869^{* *}$ \\
9 & $0.755^{* *}$ & 22 & $0.528^{* *}$ & 35 & $0.754^{* *}$ \\
10 & $0.639^{* *}$ & 23 & $0.490^{* *}$ & 36 & $0.711^{* *}$ \\
11 & $0.526^{* *}$ & 24 & $0.655^{* *}$ & 37 & $0.842^{* *}$ \\
12 & $0.674^{* *}$ & 25 & $0.535^{* *}$ & 38 & $0.745^{* *}$ \\
13 & $0.525^{* *}$ & 26 & $0.676^{* *}$ & 39 & $0.680^{* *}$ \\
\hline
\end{tabular}

${ }^{*}$ Significant at 0.01 .

Table 4. Cronbach's alpha reliability for each domain of the questionnaire with the total sum.

\begin{tabular}{clcc}
\hline No. & Domain & No. of items & Cronbach's alpha \\
\hline 1 & The skills of the general framework of the study & 13 & 0.92 \\
2 & The skills of writing the theoretical background and the literature review & 10 & 0.919 \\
3 & The procedures of the study methodology & 8 & 0.979 \\
4 & The skills of the writing the study outcomes and recommendations & 8 & 0.942 \\
Total items of the study tool & 39 & 0.968 \\
\hline
\end{tabular}

Table 5. Final list of the study skills of educational research.

\begin{tabular}{|c|c|c|}
\hline No. & Domain & Skills of educational research \\
\hline 1. & & I have the ability to write an interesting introduction to the research. \\
\hline 2. & & I have the ability to provide a rationale for presenting the study problem. \\
\hline 3. & & I have the ability to derive specific and comprehensive sub-questions from the research problem. \\
\hline 4. & & I have the ability to clearly distinguish between research objectives and significance. \\
\hline 5. & & I have the ability to choose the hypotheses suitable for the research. \\
\hline 6. & & I have the ability to formulate research hypotheses in a correct scientific manner. \\
\hline 7. & The skills of the general & I have the ability to formulate operational definitions for the key terms of the study. \\
\hline 8. & & I have the ability to clarify the limits of the study accurately. \\
\hline 9. & & I have the ability to distinguish between different types of study variables. \\
\hline 10. & & I have the ability to work out tables and forms needed in the study. \\
\hline 11. & & I have the ability to use good words and appropriate grammar for the research content. \\
\hline 12. & & I have the ability to document references and quotations easily according to scientific method. \\
\hline 13. & & I have the ability to choose the appropriate lines and margins for searching. \\
\hline 14. & & I have the ability to collect the information necessary to build the theoretical background. \\
\hline 15. & & I have the ability to divide the theoretical background based on the study variables. \\
\hline 16. & & I have the ability to write appropriate subheadings for the theoretical framework domains. \\
\hline 17. & $\begin{array}{l}\text { The skills of writing the } \\
\text { theoretical background }\end{array}$ & $\begin{array}{l}\text { In the commentary on the theoretical framework, I highlighted the differences and the similarities } \\
\text { of the previous studies. }\end{array}$ \\
\hline 18. & and the literature review & I have the ability to determine the appropriate previous studies for my study. \\
\hline 19. & & I have the ability to divide previous studies in non-overlapping domains. \\
\hline 20. & & $\begin{array}{l}\text { I have the ability to connect the domains of previous studies with the domains of the theoretical } \\
\text { framework }\end{array}$ \\
\hline
\end{tabular}


Table 5. Continues.

\begin{tabular}{|c|c|c|}
\hline 21. & & I can summarize previous studies in an appropriate manner to my study. \\
\hline 22. & & I highlight the aspects of the agreement and different in previous study. \\
\hline 23. & & I can write comprehensive and appropriate comment on the previous studies. \\
\hline 24. & & I can determine the appropriate approach to the subject of my study. \\
\hline 25. & & I can describe and identify the population of the study. \\
\hline 26. & & I have the ability to determine the best sampling methods for the study. \\
\hline 27. & The procedures of the & I have the skills to build the study tools correctly. \\
\hline 28. & study methodology & I can formulate the items of the study tools correctly. \\
\hline 29. & & I have the ability to adapt the tools of the study and check reliability and validity. \\
\hline 30. & & I have the ability to analyze data using appropriate statistical software (e.g. SPSS programs). \\
\hline 31. & & I can describe the steps of conducting the study from the beginning to the end. \\
\hline 32. & & I can interpret the results in a sound scientific manner. \\
\hline 33. & & I can organize results of the study based on the study questions and hypotheses. \\
\hline 34. & & I have the ability to link the study results to each other. \\
\hline 35. & The skills of writing the & I have the ability to link the results of the study to the results of previous studies. \\
\hline 36. & study outcomes and & I have the ability to link the results of the study to the theoretical framework. \\
\hline 37. & & I can distinguish between research recommendations and proposals. \\
\hline 38. & & I can formulate appropriate scientific recommendations for the results. \\
\hline 39. & & I can suggest further studies. \\
\hline
\end{tabular}

\section{Results of the second question}

The second question is stated as "To what extent do postgraduates of Faculty of Education at the Islamic University of Gaza master educational research skills from their perceptions?"

Table 6 shows the statistical averages and standard deviation of domains of the study instrument. The mean of the domains of the study instrument ranges from 3.66 to 4.20 . The total value of the items is 3.98. All these averages are high levels except the third domain, which is moderate range. It is obvious that the second domain, "The skills of writing the theoretical background and the literature review" had the highest mean which is 4.20. This tells that the postgraduate students master the skills of writing the theoretical background and the literature review. The domain that follows is "The skills of the general framework of the study," which had an average of 4.16. This domain includes general skills such as writing documentation, references, hypotheses and questions. These skills are highly focused in the courses that are taught to postgraduate students. The third rank is "The procedures of the study methodology". It got an average of 3.90. This domain includes skills such as determining the appropriate method, sample and population. These skills require researchers to dig deeper into scientific theses and researches. These skills also require researchers to understand the problem of the study to determine the appropriate method and to build the study tools that require high efficiency by the researcher and a lot of training on this type of skills. The last domain is
In order to answer the second question, the researchers calculated the arithmetical averages and the standard deviations of the degree of mastering educational research skills by the postgraduate students of the Faculty of Education at the Islamic University of Gaza. Table 6 clarifies the results reached.

"The skills of the writing the study outcomes and recommendations". That domain got an arithmetic average of 3.66 as it represents the lowest arithmetic mean among the domains. The skills of writing the study outcomes and recommendations, the most complex skill face postgraduates as these skills require an effort to deeply analyze the interpretation of the results, not just narrating. They also require the ability of linking the results of the study to the results of the previous studies.

\section{Results of the third question}

The third question was stated as "What are the ways to enhance postgraduates of Faculty of Education at the Islamic University of Gaza with the educational research skills from their perceptions?"

To answer this question, the researchers calculated the frequencies for each proposal submitted by the postgraduate students to the open question at the bottom of the study tool. This open question was regarding ways to enhance the educational research skills.

Table 7 shows that the aspect which should be enhanced is item no. 1 "Focusing on the practical aspect 
Table 6. Degree of mastery to educational research skills among postgraduate students according to the arithmetic averages of the study instrument domains.

\begin{tabular}{clcccc}
\hline No. & Domain & Mean & St. & Degree & Rank \\
\hline 1 & The skills of the general framework of the study & 4.2 & 1.21 & High & 2 \\
2 & The skills of writing the theoretical background and the literature review & 4.16 & 1.03 & High & 1 \\
3 & The procedures of the study methodology & 3.9 & 1.2 & High & 3 \\
4 & The skills of writing the study outcomes and recommendations & 3.66 & 1.11 & Moderate & 4 \\
Total items of the study tool & 3.98 & 1.21 & High & - \\
\hline
\end{tabular}

when teaching scientific research courses." It is the highest needed aspect among the postgraduates. It got $42.11 \%$ of the responses. Postgraduates need to strengthen their practical aspects to be parallel to the theoretical aspect.

The second proposal by which postgraduates' enhance their educational research skills is "Training on statistical programs that are suitable to be used in their research". It got $19.88 \%$ of the responses. They need training on the SPSS program that is widely used by postgraduate students in the Faculty of Education. This training comes through teaching statistical courses or through the provision of training courses on these programs during the postgraduates' study period. This will also help them in their preparation to their scientific theses as described in the second and the third item stated in the table.

The proposal no. 3 is "Provide training courses for postgraduate students besides to their university regular courses to develop their research skills". It got 18.67 of the responses. This is also of great importance as it is related to practical aspects the postgraduates need.

Item no. 4 is "Teaching scientific research course and seminar course by specialized professors ". It got $16.26 \%$ of the responses. It is known that if these courses are taught by specialized professors, the postgraduates will do better in the educational research.

Item no. 5 "Guiding postgraduate students to use databases and scientific journals." It got $15.06 \%$ of the responses. Databases and scientific journals are the main sources for the previous studies used by students. They rely on them during the preparation of scientific theses or when publishing their various research. Journals are considered one of the most significant sources of information and knowledge to various fields.

Item no. 6 "Conducting study days for students of higher education". It got $6.02 \%$ of the responses. On these days, postgraduates are given the opportunity to train and practice the preparation of educational research, and get benefit from the experiences of other academics who participate.

Table 7. Percentages of the views of postgraduates to the ways to develop the educational research skills.

\begin{tabular}{clc}
\hline No. & Items & $\%$ \\
\hline 1 & Focusing on the practical aspect when teaching scientific research courses & 42.11 \\
2 & Training on statistical programs that are suitable to be used in their research & 19.88 \\
3 & Provide training courses for postgraduate students besides to their university regular courses to & 18.67 \\
4 & develop their research skills & 16.26 \\
5 & Geaching scientific research course and seminar course by specialized professors & 15.06 \\
6 & Conducting study days for students of higher education & 6.02 \\
\hline
\end{tabular}

\section{Results of the fourth question}

The fourth question is stated as "Are there any statistically significant differences in the average responses of postgraduates in Faculty of Education at the Islamic University of Gaza towards their mastery of educational research skills due to gender variable (male female)?

To answer the fourth question, the researchers formulated the following null hypothesis: "There are no statistically significant differences in the average responses of postgraduates in Faculty of Education at the Islamic University of Gaza towards their mastery of educational research skills due to gender variable (male female)."

Table 8 showed that the calculated value $(\mathrm{t})$ is 0.406 . It is less than the tabled $(\mathrm{t})$ which is 1.984. Thus, we accepted the null hypothesis and that there are no statistically significant differences in the average responses of postgraduates at Faculty of Education at the Islamic University of Gaza towards their mastery of educational research skills due to gender variable (male - 
Table 8. Results of t-test for two independent samples to examine the level of differences according gender.

\begin{tabular}{llccccc}
\hline Variable & Category & Number & Mean & St. & T value & Sig \\
\hline \multirow{2}{*}{ Gender } & Male & 42 & 158.83 & 16.06 & \multirow{2}{*}{0.406} & \multirow{2}{*}{0.685} \\
& Female & 67 & 157.16 & 23.38 & & \\
\hline
\end{tabular}

*Tabled $t$ is 1.984 .

female).

\section{Results of the fifth question}

The fifth question is stated as "Are any statistically significant differences in the average responses of postgraduates in Faculty of Education at the Islamic University of Gaza towards their mastery of educational research skills due to degree variable (master - Ph.D.)?"

In order to answer the previous question, the researcher formulated the following null hypothesis: "There are no statistically significant differences in the average responses of postgraduates at Faculty of Education at the Islamic University of Gaza towards their mastery of educational research skills due to degree variable (master - Ph.D.)."

The hypothesis is tested by using t-test for two independent samples as shown in Table 9.

Table 9 shows that the calculated value (t) is 3.021 . It is bigger than the tabled ( $\mathrm{t}$ ) which is 1.984. The results are in favor of the biggest mean (170.05) of the doctorate level. This means that we reject the null hypothesis and accept the alternative hypothesis. Thus, it could be concluded that there are statistically significant differences in the average responses of postgraduates at Faculty of Education at the Islamic University of Gaza towards their mastery of educational research skills due to degree variable (master - Ph.D.) in favor of Ph.D. students.

Table 9. Results of t-test for two independent samples to examine the level of differences according to the level of study (master or Ph.D.).

\begin{tabular}{llccccc}
\hline Variable & Level & Number & Mean & St. & T value & Sig \\
\hline \multirow{2}{*}{ Gender } & Master & 89 & 155.06 & 16.06 & \multirow{2}{*}{3.021} & \multirow{2}{*}{0.003} \\
& Doctorate & 20 & 170.05 & 23.38 & & \\
\hline
\end{tabular}

*Tabled $t$ is 1.984 .

\section{DISCUSSION}

In this part, the researchers discuss the results of the five questions as follows:

\section{Discussion of the first question}

The results of the first question showed a list of the educational research skills. As it is shown in Table 5, the domains and the items of the list cover the whole aspects of the educational research. These domains and aspects are closely related to the educational research. There are shared aspects with other types of researcher. The general aspects of all researches are the introduction, the questions of the study, significance, literature review, methodology, and results. However, in the educational research there are statistical techniques that should be mastered by postgraduates. There should be hypotheses that are derived from the study questions. Data should be presented in tables. There should be treatment to study variables. In conclusion, the researchers can tell that these skills are skills of educational research that could be used as standards to measure any educational research.

\section{Discussion of the second question}

The results of the second research showed that there is a high range of mastering educational research skills. As shown in Table 6, the highest domain of skills is 'The skills of writing the theoretical background and the literature review'. This could be interpreted as there is no practice in this domain. The students also showed their difficulty in writing the study outcomes and the recommendations. This could be referred to the weak side of practice also. Students rarely publish or write articles or papers at the stage of master or doctorate. The researchers commented that the nature and the procedure of writing a research paper at the Palestinian universities do not require diving deeply in analysis. It is a process of compiling information in one research and writing some comments on the results.

The results of second question are consistent with the study of Al Rafiae (2016) which showed that 
postgraduates possess advanced skills in scientific research. However, the results of this question are inconsistent with Al-Muqbel (2012), Al-Qahtani (2013) and Al-Muqbel (2012). These studies showed low level of research skills among their respondents.

\section{Discussion of the third question}

The third question primarily focused on proposing ways for developing educational research skills. The respondents focused on the practical aspects of writing a research. The researchers of the current research think that all the respondents' answers revolve around one aspect which is the practical aspect. The postgraduates are in dire need for this. This study is in conformity with Feldon et al. (2011) which stated that postgraduates who write researches have greater improvement in their abilities to generate testable hypotheses and design valid experiments. The results are with Al-Qahtani (2013) that confirmed the importance of practical aspects.

\section{Discussion of the fourth question}

The results indicated that there is no difference attributed the gender of the postgraduates. Both genders have the same level of mastery to the educational research skills. The study is in conformity to the study of Al Rafiae (2016) that showed no weakness level among the females' postgraduates. The researchers justify the finding of this question that the graduates of both genders (males and females) study the same courses and take the same training courses. They are often taught by the same teacher of the course at the Faculty of Education at the Islamic University of Gaza.

\section{Discussion of the fifth question}

The results indicated that the Ph.D. showed more progress in mastering the educational research. The researcher attributed this to the fact that the doctoral students took many courses during the master degree as well as in their current stage of doctorate studies. The doctorate students prepared researches and studies more than the students at the master level. It is normally to see Ph.D. students have more skills in the educational research.

\section{Findings}

The study reached the following findings:

1. The level of mastering educational research skills from the postgraduates' perception is high.

2. The postgraduates stressed great importance to having space for practical aspects of the educational scientific research.

3. There is no difference between male and female in the degree of mastering the educational research skills.

4. The study showed that the Ph.D. students have a higher degree of mastering the educational research skills compared with the master students.

\section{Conclusion}

The study can conclude that there is a high level of mastering educational research skills among the Palestinian postgraduates. At the same time, the postgraduates showed their need to the practical aspects of conducting an educational research. The study also indicated that there is no difference among male and female student in the level of mastering educational research skills as they have the same courses, professors, environment and study plan. The study concluded that the Ph.D. students showed more advance level that the master students as the first have more experience in educational research and experienced a previous research degree.

The researchers can also comment that the quality of research in Palestine is weak relative to the international researches. The results of the research indicate that 'high level' is from the postgraduates' perceptions and it might be different if it is measured by other respondents. The study was applied on postgraduates who experience the Arab and Palestinian nature of writing research paper. To explain more, the researches in Palestine may not meet the international standards of writing a research paper. Students write poor researches and getting the professors' consents on these researches. When distributing the questionnaire to the students, they showed high level of mastering educational research skills, while in fact they have an advance level in the kind of the Arab and Palestinian researches that are to some extent away from the international standards.

\section{Limitations of the study}

First of all, the research was conducted during the first semester of the year 2017/2018. The research selected the postgraduates at master and Ph.D. level at Faculty of Education at Islamic University of Gaza.

Second, the number of the participants is small, only one hundred and five students. This is out of the whole number of the postgraduates of the education faculties in Palestine.

Third, as the questionnaire is designed to measure the postgraduates' perceptions towards their level of mastering the educational research skills, it may not give exact information regarding the real level. Postgraduates' professors, exams results, and accumulative averages ought to be checked to have real result about their level. 
The analysis of their university papers and articles might be evaluated also.

\section{RECOMMENDATIONS}

In light of the study results, the researchers offer the following recommendations:

1. To update the courses that are taught to graduate students such as scientific research methods, research seminar, and statistics to focus on the practical aspects of theses.

2. To direct the graduate students towards the use of databases, scientific journals, publishing houses and other sources as they provide students with many skills.

3. To hold training courses for postgraduate students to develop their research skills in the field of educational research.

4. To provide scientific manuals that include the conditions and bases that graduate students should follow in the preparation of their scientific theses.

5. To teach courses related to research methods in a specific specialization in this field.

\section{Recommendations for future studies}

1. The researchers recommend other researchers to conduct studies that evaluate some of the Palestinian educational researches to show the quality of these researches.

2. To conduct a study to show the quality of the Arab educational theses in terms of standards of writing scientific theses. The researchers can select a certain number of theses from certain Arab countries.

3. Conducting a similar research using university professors of education departments to take their views regarding measuring the postgraduates' mastery level of educational research skills at Palestine universities.

\section{REFERENCES}

Al Rafiae, Y. (2016). The extent to which students of graduate studies at King Khalid University have the skills of scientific research and its problems and ways to overcome from their point of view. International Specialized Educational Journal, 5(9): 425-454.

Al-Agha, I. (2000). Educational Research: Elements, Methods, Tools. Al Amal Trading Press: Gaza, Palestine.

Al-Muqbel, A. (2012). The scientific research skills among the students of the Faculty of Education at Taibah University: The reality and mechanisms to upgrade. Journal of the Union of Arab Universities, 62: 35-71.

Al-Qahtani (2013). Research skills of postgraduate students at the Faculty of Education at King Saud University. Journal of Educational Sciences, 21(4): 283-333.
Al-Qasim, W. (2007). Educational Research. Riyadh: King Saud University.

Ammar, I. (2015). Developing the skills of educational research for postgraduate students in the Faculties of Education in Egypt in light of the experiences of some countries. Educational Journal, 41: 295325.

Atwan, A. (2011). The Competencies of Scientific Research among Graduate Students in Faculties of Education in Palestinian Universities. The Scientific Research Conference, Concepts - Ethics Functioning, Islamic University, Gaza, 253 - 282.

Australian Council of Deans of Education (ACDE) (2005). Research Quality Framework, Response to the Issues paper, DEST, Canberra.

Barghouti, E., and Abu Samra, M. (2007). Difficulties of scientific research in the Arab world. IUG Journal of Educational and Psychological Studies, 5(2): 1133-1155.

Ben Tarif, A., and Tweissi, Z. (2017). Current situation of scientific research at the University of Jordan from the viewpoint of graduate students. Arabic Journal for quality Assurance, 10(29): 113-132.

Braimoh, D., and Alade, E. (2005). Research and Publishing in Academia: A Prerequisite for Assuring Quality in Higher Education. US-China Education Review, 2(9), 5-13.

Buckingham, J. (2005). The Problem with Educational Research. The Australian, Feb 18, p.18.

Clark, C. (2013). The structure of educational research. British Educational Research Journal, 31(3): 289-308.

Feldon, D., Peugh, J., Timmerman, B., Maher, M., Hurst, M., Strickland, D., and Stiegelmeyer, C. (2011). Graduate students' teaching experiences improve their methodological research skills. Science, 333(6045): 1037-1039.

Kaddoumi, M. (2016). Activating the elements of educational research in Palestinian Universities in light of the requirements of community service. Jerash Journal for Research and Studies, 1(17): 381-402.

Kojak, K. (2007). Common Mistakes in Educational Research. Cairo: The World of Books Publishing House.

Lulu, F., and Abu Camille, R. (2013). Alternative Perceptions of the Concepts of Educational Scientific Research among Graduate Students in the Faculties of Education in Palestinian Universities. Conference of Graduate Studies: Reality and Prospects of Reform and Development convened at The Islamic University of Gaza on 2930 April.

Metcalfe, A., and Fenwick, T. (2009). Knowledge for whose society? Knowledge production, higher education, and federal policy in Canada. Higher Education, 57(2): 209-225.
Citation: Assaff, M. M. O., and Aburezeq, K. A. (2018). Postgraduates' perceptions regarding their mastery level of educational research skills at the Palestinian faculties of education and ways to develop these skills. African Educational Research Journal, 6(3): 148-159. 